\title{
Kapselendoskopie kann Koloskopie nicht ersetzen
}

Für die Dünndarmdiagnostik, insbesondere zum Nachweis einer Blutungsquelle im Dünndarm, steht heute die Kapselendoskopie zur Verfügung. Dass eine Kolonkapselendoskopie die konventionelle Koloskopie ablösen könnte, ist nach den Ergebnissen einer neueren Studie jedoch unwahrscheinlich.

- Im Rahmen dieser Studie wurde bei 328 Patienten zunächst nach einer definierten Kolonreinigung eine Kapselkoloskopie durchgeführt. Am selben oder am darauffolgenden Tag wurde eine $\mathrm{Vi}$ deokoloskopie angeschlossen.

Bei dem Aufspüren von polypösen Veränderungen war die Kapselendoskopie der konventionellen Koloskopie deutlich unterlegen, d.h. es wurden nur 64\% der Polypen mit einem Mindestdurchmesser von $6 \mathrm{~mm}$ und $73 \%$ der fortgeschrittenen Adenome mit einer
Mindestgröße von $1 \mathrm{~cm}$ erkannt. Auch wurden bei der Kapselendoskopie nur 14 von 19 koloskopisch nachgewiesenen Karzinomen entdeckt.

\section{Kommentar}

Auch wenn die konventionelle Koloskopie für den Patienten sicher belastender ist als die Kapselendoskopie, dürfte nach diesen Ergebnissen zumindest zum jetzigen Zeitpunkt die Kapsel keine sinnvolle Alternative zum Koloskop sein, da ein Viertel der relevanten Befunde übersehen wird. Somit ist und bleibt die konventionelle Videoendoskopie der Goldstandard für die Kolondiagnostik.

P. Stiefelhagen =
Die konventionelle Videoendoskopie ist und bleibt der Goldstandard für die Kolondiagnostik.

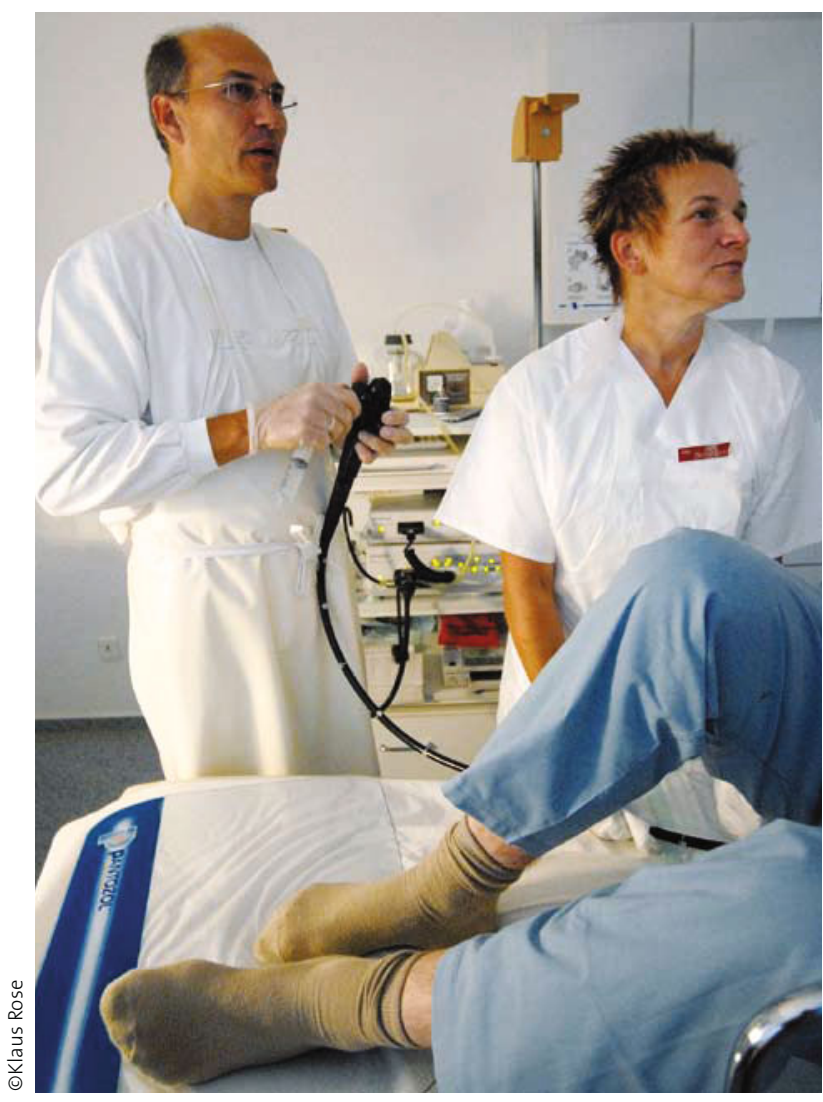

